\title{
A Survey on the Self-regulation Efficacy in DUT's English Blended Learning Context
}

\author{
Haibo Shen \\ School of Foreign Languages, Dalian University of Technology, Dalian, China \\ Email: haibo0607@yahoo.com.cn \\ Wenyu Liu \\ School of Foreign Languages, Dalian University of Technology, Dalian, China \\ Email: wenyulaoshi@gmail.com
}

\begin{abstract}
A new trend of teaching modality of blended learning (BL) has emerged with the fast development of modern technology of communications and the application of the technology in education. Despite the popularity of BL among social researchers, relatively few studies have been conducted in respect of students themselves. A survey was conducted on the current situation of students' self-regulation efficacy in English learning in a BL context in Dalian University of Technology (DUT); and the results indicate show that students in DUT do not possess strong self-regulatory ability in English learning in the BL context, while the outcome also implies that postgraduates' self-regulatory ability is stronger than that of undergraduates. The outcome also supports the argument that students' self-regulatory ability can be enhanced through teaching, learning and practice. Several empirical suggestions are provided that may be helpful for the English teaching instructors in order to enhance students' self-regulatory ability in English learning in a BL context based on the findings.
\end{abstract}

Index Terms - blended learning, self-regulation, survey, suggestions for teaching

\section{INTRODUCTION}

\section{A. Research Background}

With the development and optimization of modern communication system of the computer and the Internet, the use of the computer and the Internet in higher education has greatly increased in recent years. The widely adoption of modern technologies of information and communications in the education field has exerted a great impact on the traditional structure of teaching and also has brought new ideas about teaching and learning. This new change in the education field is accepted by most researchers as Blended Learning (BL), or Hybrid Learning (as some scholars call it). BL, a new modality of teaching combining the traditional teaching method and online learning, which was first emerged from the process of training employees in enterprises, has gained growing attention. Blended Learning has been widely applied to elementary and higher education and has become a constant heated topic for social workers, especially those concerning education.

Compared with the traditional face-to-face teaching-learning method or e-learning mode, BL gains great advantages for it is the hybrid of the two. Regarding to its advantages, many universities in China have also introduced this new teaching modality to their faculties and students in order to achieve better performance in students' learning. As a result, a great number of essays on the definition, structure, advantages and effectiveness of BL have emerged during the past few years. Scholars have universally recognized the significance and necessity to adopt and promote BL in teaching activities. Nevertheless, comparably few studies have been undertaken on the self-regulation efficacy in respect of students, which is a fundamental factor for BL since BL emphasizes on the self-regulation and self-learning (which is the basis for the realization of BL). Therefore, the paper intends to probe into the students' self-regulation efficacy in a blended learning context.

\section{B. Research Purpose}

American Society for Training and Development (ASTD) has listed BL as one of the ten most important emerging trends in the knowledge dissemination industry. Besides, in its final report based on meta-analysis of more than one thousand empirical studies of online learning (BL in this paper) from 1996 to 2008, the US Department of Education pointed out that BL is the most effective way of learning compared with face-to-face teaching or e-learning,. Meanwhile many other studies by scholars from both home and abroad have also confirmed the necessity of applying BL in higher education. What is urgent at present is how to better apply BL and improve its effectiveness in higher education, which makes the study of the current situation of the application of BL on campus critical. In recent years, Chinese scholars have conducted quite a number of experiments and studies in order to explore how to improve the design of a curriculum, i.e. the percentage of traditional learning and online learning in a course, to get better results. Achievements 
have been made on the basis of those studies. Nevertheless, more studies of BL focusing on students should be carried out to achieve more. This paper is composed out of this concern. The author intends to provide a comprehensive illustration of the current situation of students' self-regulation efficacy of English learning in a BL context in Dalian University of Technology (DUT) and offer some empirical suggestions on the improvement of English teaching on this campus based on an investigation of the students and the outcome of the survey. The analysis and suggestions may be helpful for English instructors to improve students' self-regulation efficacy in English learning in a BL context in future teaching activities.

\section{LITERATURE REVIEW}

\section{A. Blended Learning}

1. Definition of Blended Learning

In recent years, BL has been a hot topic in employee training programs, as well as in formal education. Despite its popularity among enterprises and social researchers, the definition of BL has long been in dispute. Different scholars may give different definitions or descriptions of BL focusing on different aspects.

Richard Lynch and Myron Dembo pointed out that "blended education is a form of distributed education, utilizing both distance and face-to-face modalities to deliver instruction" (Lynch \& Dembo, 2004). Jessica S. Ayala defines BL as the purposeful integration of traditional (i.e. face-to-face) and online learning in order to provide educational opportunities that maximize the benefits of each platform and thus more effectively facilitate student learning. (Ayala, 2009) Anita Pincas \& Gunter Saunders mentioned in their paper "blended courses" are "part face-to-face and part distance or online). (Pincas \& Saunders, 2003) Margaret Driscoll provided four different concepts for the term Blended Learning as follow: (1)to combine or mix modes of web-based technology (e.g. live virtual classroom, self-paced instruction, collaborative learning, streaming video, audio, and text) to accomplish an educational goal; (2)to combine various pedagogical approaches (e.g. constructivism, behaviorism, cognitivism) to produce an optimal learning outcome with or without instructional technology; (3)to combine any form of instructional technology (e.g. videotape, CD-ROM, web-based training, film) with face-to-face instructor-led training; (4)to mix or combine instructional technology with actual job tasks in order to create a harmonious effect of learning and working. (Driscoll, 2002) He Kekang holds that $\mathrm{BL}$ is the result of combination the advantages of both traditional leaning method and e-learning (i.e. digital or web-based learning) and BL thus can emphasize the guiding role of professors and cultivate the initiation of students at the same time. (He, 2004)

Based on all the definitions offered by researchers from home and abroad, the author defines BL in this paper as a teaching and learning modality that combines traditional face-to-face teaching method and any form of instructional technology (e.g. videotape, CD-ROM, web-based materials) in order to maximize both the guidance of professors and the initiation of students.

2. Advantages of Blended Learning

As the definition of BL suggests, BL is blended on the basis of elaborate evaluation of all factors concerning learning like time, place, instructors' teaching style and individual differences of students instead of simply mixing the traditional and online learning. Thus the adoption of BL has several advantages over traditional face-to-face learning or mere e-learning (or online learning).

First, students can have more choice and control over their study but under the guidance and instruction of their instructors at the same time, which will undoubtedly cultivate the creative and initiative spirits of students. Second, in a BL context students can make use of the abundant materials on the Internet and have a better understanding of the substantive materials with the help of professors in a face-to-face classroom. (Cui, 2005) Third, a BL context can provide students a greater opportunity to interact with each other and with their professor and thus form a stronger sense of community. (Rovai \& Jordan, 2004) Last but not least, on average, students in a BL context would perform better than those take mere face-to-face classes or online classes, i.e. BL is the most effective way of learning among the three modalities. (Means et al, 2009) This has been proved by the US Department of Education in its final report based on meta-analysis of more than one thousand empirical studies of online learning from 1996 to 2008.

3. Determinants of Blended Learning

There are many factors that may affect the effectiveness and results of BL. First, since BL makes use of modern technology of communications, there is a high demand for the access to the computers and the Internet. Second, the right teaching method can better inspire students. (Li, 2008) Third, the design of the course should be considered carefully. The proportion of the face-to-face part and online part may greatly influence the effectiveness of BL. (Ayala, 2009) Fourth, students are the centre of learning activities. Compared with the instructor-centered traditional teaching modality, the self-regulation of students seems more significant. (Lynch \& Dembo, 2004) What is more, most Chinese students have been used to relying on their instructor in the process of learning, which requires strengthening and improving students' ability of self-learning for the success of BL. Being the core component of self-learning, self-regulation is one of the most elements to achieve a success in a BL context, especially from the learners' own respective. In summary, even though a number of elements seem important to the learning outcome, a successful learning can only be achieved by fulfilling all of the affecting factors. 


\section{Study and Practice of Blended Learning}

Since its first emergence in corporation employee training programs in 1990s, BL has been a continuously heated research focus in secondary and higher education. Numerous studies have been conducted concerning its effectiveness and advantages over traditional teaching approach, as well as course designs. According to the final reports of the US Department of Education's meta-analysis of more than one thousand empirical studies of online learning from 1996 to 2008, no less than 99 studies had been conducted using an experimental or quasi-experimental design and objectively measured student learning outcomes between the year 1996 and 2008, not to mention those focusing on the theory construction and improvement. (Means et al, 2009) Besides, a rough search in the database of China National Knowledge Internet can result in more than 170 papers on BL, most of which also focusing on the refinement of the theoretical framework of BL, its effectiveness or the design of courses.

Overwhelming research results have proved the effectiveness of BL and its advantages over traditional face-to-face learning or e-learning. Many researchers also provided some practical suggestions about the course design in a BL context. Despite the fact that all previous studies have greatly benefited the implement and improvement of BL in education, relatively little attention has been paid to the agent of learning, i.e. learners themselves. Only a handful of papers were conducted in respect of students' motivations, learning strategies or sense of community in a BL context. More and further studies on learners themselves are in necessity.

\section{B. Self-regulation}

\section{Definition of Self-Regulation}

Zimmerman defined academic self-regulation as the degree to which learners are meta-cognitively, motivationally, and behaviorally active in their learning process. (Zimmerman, 1989) He also pointed out that self-regulation is "the self-directive process by which learners transform their mental abilities into academic skills" and the notion of self-regulation "refers to self-generated thoughts, feelings, and behaviors that are oriented to attaining goals". (Zimmerman, 2002) Lynch and Dembo argued that "self-regulated learners are active, adaptive constructors of meaning who control important aspects of their cognition, behavior, and environment in attaining their learning goals. (Lynch \& Dembo, 2004) Dong Qi and Zhou Yong, two Chinese scholars, defined students' self-regulation as students constantly plan, regulate, check, evaluate, reflect, control and adjust themselves in the whole process of learning in order to improve learning efficiency and achieve learning goals. (Dong \& Zhou, 1994) In general, self-regulated learner would use specified strategies including adjust their internal feelings and external environment in order to achieve their academic goals on the basis of self-efficacy perceptions in the whole process of learning.

\section{Significance of Self-Regulation in Learning}

Learning is an extremely complicated system comprising a number of correlated and interactive elements. These elements include students' own factors like individual intelligence, learning ability, learning style, motivation and characters, as well as the environmental factors like learning tasks, materials, place, time, instructors and classmates. A successful learning activity can be achieved only when all these factors are properly and efficiently interacted, which requires constantly active and scientific control and adjust of these factors, i.e. self-regulation. (Dong \& Zhou, 1994) Many related studies have proved the fact that students with high self-regulatory abilities can achieve more and better in learning. Therefore self-regulation is a critical factor determining the learning outcome.

Furthermore, just as Zimmerman mentioned, a major function of education is the development of lifelong learning skills. (Zimmerman, 2002) After finishing higher education and entering society, formal or informal learning will never decease. Learning important skills related to one's job is crucial to the success of one's career. Thus the self-regulatory ability is an indispensable one to one's career and also to the realization of one's values.

3. Features of Self-Regulation

Different learners have different learning styles and learning habits. However, it is generally accepted that self-regulated learners do share some common characteristics despite their individual diversity. Several main traits possessed by all self-regulated learners are listed below.

Self-regulated learners have high self-awareness of their self-regulation in the whole process of learning. They are different from those who are not self-regulated in that the control and adjust of themselves are always self-initiated instead of being forced by external factors. (Dong \& Zhou, 1994)

First, they show a high sense of academic self-efficacy and a high desire for achieving certain learning goals. They are also more capable of controlling and modifying them to the requirements of the task and of the specific learning situation.

Second, they can properly assign the time and efforts to be used to fulfill the task, choose a favorable environment for study.

Third, they are familiar with and know how to use a series of cognitive strategies in accordance to specific task and situation in order to improve the efficiency of learning and to achieve all the goals of learning.

In summary, all self-regulated learners view themselves as agents of their own behavior and learning, believing learning is a proactive process. They are self-motivated and can adopt efficient strategies to achieve desired academic results. (Montalvo \& Torres, 2008)

4. Determinants of Self-Regulation

Based on a review of literature, five self-regulatory attributes were highlighted as main determinants of the success of 
learning: motivation, meta-cognition, time and environment management, help seeking and Internet self-efficacy. Each of these attributes is important to the efficiency of self-regulation in learning and they are also correlated and interactive. The definition and description of these five attributes also compose the theoretical framework of self-regulation for the questionnaire adopted in this survey.

a. Motivation

Motivation for learning stems from students' beliefs about learning. A universally received theory of motivation is Printrich's expectancy-value model, which is comprised of three motivational components: expectancy component, value component and affective component. The expectancy component involves students' beliefs that they are able to perform the task and that they are responsible for their own performance. The value component involves students' goals for learning and their beliefs about the importance and interest of the task. The affective component concerns students' affective or emotional reactions to the task, which is always referred to as test anxiety. (Pintrich \& De Groot, 1990) In this study the first two components are taken into consideration. Thus motivation in this study mainly concerns two components: self-efficacy and intrinsic goal.

Self-efficacy is defined by Zimmerman as perceptions about one's capabilities to organize and implement actions necessary to attain designated performance of skill for specific tasks. (Zimmerman, 1989) Pintrich pointed out students with high self-efficacy can better adopt self-regulatory strategies to achieve learning goals and thus self-efficacy has a reciprocal relationship with learning outcomes. He defined goal orientation as a learner's perception of the reason why taking this course and his or her general goals or orientation toward a course. Intrinsic goal orientation is defined as "the degree to which the student perceives herself to be participating in a task for reasons such as challenge, curiosity, and mastery". (Pintrich et al, 1991) Numerous studies show that students who have setting goals usually adopt more cognitive strategies and show higher levels of persistence in the learning process.

Motivation, comprising self-efficacy and intrinsic goals in this study, is a key element of self-regulated learning since highly motivated students show better mastery of cognitive strategies and have better learning outcomes, which has been proven in the survey by Wenyu Liu and Ji-an Zha (2009).

b. Meta-cognition

Meta-cognition is usually simply defined as the awareness of and knowledge about one's own thinking. Pintrich defined meta-cognition as "the awareness, knowledge and control of cognition". (Pintrich et al, 1991) However, the notion of meta-cognition contains far more than that. According to Flavell, meta-cognition consists of both meta-cognitive knowledge and meta-cognitive experiences. (Flavell, 1987) Meta-cognitive knowledge refers to acquired knowledge about cognitive processes, knowledge that can be used to control cognitive processes. Meta-cognitive experiences involve the use of meta-cognitive strategies which are sequential processes that one uses to control cognitive activities, and to ensure that a cognitive goal could be met. (Livingston, 1997) According to Pintrich, there are three general processes that make up meta-cognitive self-regulatory activities: planning, monitoring and regulating. (Pintrich et al, 1991) Whichever analysis of meta-cognition it is, meta-cognition is a preliminary element of adopting effective learning and self-regulatory strategies and thus plays a critical role in successful self-regulated learning.

c. Time and Environment Management

Studies show that students who use their time efficiently can perform better and achieve more goals in learning process. Therefore Zimmerman pointed out that a self-regulated learner must manage one's time and use one's time efficiently. (Zimmerman, 2002) Pintrich proposed that time management involves scheduling, planning and managing one's study time. (Pintrich et al, 1991) Zimmerman regarded environmental self-regulation, which involves arranging a quiet study area for completing task, as one of the three elements of the triadic self-regulatory functioning. (Zimmerman, 1989) So in the analysis of learners' self-regulatory ability, the capability of time and environment management is indispensable.

\section{d. Help Seeking}

Another important element affecting study efficiency is the support of others. According to Pintrich, support of others includes help from both peers and instructors. (Pintrich et al, 1991) Good self-regulated learners knew when and how to seek help from others when they are in difficulty.

\section{e. Internet Self-Efficacy}

Internet self-efficacy is generally referred to as the belief of one's capabilities to organize and execute courses of Internet actions required to produce given attainments. ( $\mathrm{Li}, 2004)$ As in a blended learning context, the use of Internet is crucial. So there is a reciprocal relationship between Internet self-efficacy and self-regulation. Students with high Internet self-efficacy have few problems facing tasks related to computer and Internet. Thus it is also a key factor to measure one's self-regulatory ability in a blended learning context.

5. Study and Practice of Regulation

The concepts and perspectives of education have undergone great changes during the past 30 years and learning is conceived of as an active, cognitive, constructive, significant, mediated and self-regulated process. Most scholars agree that education should help students to be aware of their own thinking, to be strategic and to direct their motivation toward valuable goals. (Montalvo \& Torres, 2008) Thus self-regulated learning has become a current focus for research since the publication of Self-Regulated Learning and Academic Achievement: Theory, Research, and Practice. (Zimmerman, 1989) Later, Zimmerman and Schunk published several other papers on self-regulation of learning in 
succession to further probe into this area. Other scholars like Pintrich also showed great interest in self-regulation and did a number of studies on it like Handbook of Self-Regulation. Therefore, a socio-cognitive perspective of self-regulation of learning gradually formed on the basis of scientific research and study. Under such a theoretical framework of self-regulation, further empirical experiments were also conducted by scholars from both home and abroad and several general received measure instruments of self-regulation, such as the Motivated Strategies for Learning Questionnaire by Pintrich and his colleagues and Self-Regulated Learning Interview Schedule by Zimmerman and his colleagues etc., were developed as well. Currently the study on self-regulation has achieved a lot through decades' hardworking. However, investigation in self-regulation in BL, especially related empirical research, has been rare. Further study on learners' self-regulatory ability should be conducted and measures to improve such ability should be provided through scientific research.

\section{METhODOLOGY}

In this section, guided by the theoretical framework of BL and self-regulation, a questionnaire adapted from the Motivated Strategy for Learning Questionnaire (MSLQ) was used to conduct a survey on self-regulation efficacy of students learning English in a BL context. All the respondents are students having English classes that contain online learning at present on the campus of Dalian University of Technology (DUT). The questionnaire used in this survey, whose construct validity and reliability was tested by a preliminary survey, consists of two sections, including the basic individual information section and 40 items containing six subscales. In the process of analyzing the data, the statistical software Statistical Package for Social Science (SPSS) was used. Results analysis and suggestions were offered on the sound foundation of a theoretical framework and an empirical survey.

\section{A. Subjects}

On the campus of DUT, all English instructors have adopted the modality of Blended Learning in delivering the English course for non-English majors, despite the variance of the proportion of face-to-face part and computer operating part. So the author selected 570 students who are taking an English course at present in DUT as the respondents of this survey. Considering their different language learning backgrounds, all the respondents are majored in science or technology, excluding those who are majored in arts and literature.

In order to test the validity and reliability of the questionnaire used in this survey, a preliminary survey was conducted, in which 120 questionnaires were distributed to undergraduates from four classes taking the course of College English this term and 102 valid and feasible questionnaires were collected.

In the formal survey afterwards, 450 questionnaires were distributed, in which 230 pieces to undergraduates and 220 to postgraduates (either master or doctor degree candidates). In the end, 203 questionnaires answered by undergraduates and 179 pieces by postgraduates, all together 382, were collected. What should be pointed out here is that non-English major students taking an English course in DUT are mostly from grade one or grade two, which leads to the fact that almost all the respondents are grade one or two students (undergraduates as well as postgraduates).

\section{B. Instrument}

As mentioned above, motivation and some self-regulatory strategies have a reciprocal relationship with self-regulated learning and therefore learning in a BL context. Besides, students' motivations change from course to course for different reasons and thus their self-regulatory and learning strategies may also vary depending on different courses under different situations. The Motivated Strategy for Learning Questionnaire (MSLQ) was just designed within such a theoretical framework and it is different from other measure instruments in that it is designed to measure college students' motivation and self-regulated learning in a specific course. Therefore the author selected MSLQ as the original script to make her own questionnaire.

\section{The Motivated Strategy for Learning Questionnaire}

MSLQ was developed by Pintrich and his colleagues over three years and the final version underwent 10 years of development, during and after which time it was used by numerous researchers in related studies. Moreover, it has been translated into more than 20 different languages, among which the Chinese version has undergone formal assessment of validity and reliability.

MSLQ is designed to assess college students' motivational orientations and their use of different learning strategies for a college course. It contains 81 items in two sections, a motivation section and a learning strategies section. The motivation section consists of 31 items that assess students' goals and value beliefs for a course. These items can be further divided into six subscales: intrinsic goal orientation, extrinsic goal orientation, task value, control of learning beliefs, self-efficacy for learning and performances, and test anxiety. The learning strategies section is composed of 50 items in nine subscales: rehearsal, elaboration, organization, critical thinking, meta-cognitive self-regulation, time and study environment management, effort regulation, peer learning, and help seeking. (Pintrich et al, 1991)

2. Structure of the Questionnaire in This Survey

The survey instrument used in this study consists of 49 items in two sections. Section one includes nine items to collect the basic individual information of the respondents like gender, grade, average time used for the course and so on. Section two is composed of 35 items adapted from the MSLQ to assess learners' motivation and learning strategies 
and 5 items adapted from an Internet Self-Efficacy Scale (Liu, 2005) to assess learners' Internet self-efficacy. Based on the theoretical framework of self-regulation discussed above, the second section can be further divided into six subscales: intrinsic goal orientation, self-efficacy for learning and performance, meta-cognition, time and study environment, peer learning, and Internet self-efficacy. Each subscale contains 4, 8, 12, 8, 3, and 5 items respectively.

3. Scoring of the Questionnaire in This Survey

Students rate themselves on a 7-point Likert scale, from 1 (not at all true of me) to 7 (very true of me). Thus the score for one item ranges from 1 to 7 . Scores for each subscale is computed by taking the mean of the items that make up the subscale. Five items within the questionnaire are negatively worded and must be reversed before a student's score is computed. Ultimately, the overall score summing all the six subscales represents the positive wording of all items and higher scores indicate higher levels of self-regulatory ability. (Artino, 2005) The highest score for each subscale is 28 , $56,84,56,21$ and 35 respectively, and the highest final score (or the full mark) of the whole questionnaire is 280 (as the table 1 shows in detail).

TABLE 1.

SCORING OF THE QUESTIONNAIRE

\begin{tabular}{|l|l|l|l|}
\hline subscale & items contained in each subscale & number of items & Score of each subscale \\
\hline Intrinsic goal orientation & $1,6,9,10$ & 4 & $4-28$ \\
\hline Self-efficacy for learning & $2,3,4,5,7,8,11,12$ & 8 & $8-56$ \\
\hline Meta-cognition & $13,16,17,19,23,24,25,26,27,31,33,34$ & 12 & $12-84$ \\
\hline Time and study environment & $15,18,22,28,29,30,32,35$ & 8 & $8-56$ \\
\hline Help seeking & $14,20,21$ & 3 & $3-21$ \\
\hline Internet self-efficacy & $36,37,38,39,40$ & 5 & $5-35$ \\
\hline total & $1-40$ & 40 & $40-280$ \\
\hline
\end{tabular}

4. Construct Validity

Since the instrument used in this study was adapted and developed on the basis of two questionnaires, the validity and reliability were tested in a preliminary experiment of 102 feasible answer sheets. The data were analyzed with the help of the statistical software Statistical Package for Social Science (SPSS).

The KMO and Bartlett's test shows that the KMO measure of sampling adequacy is 0.784 and the significance is 0.000 , which proves the component analysis feasible. Therefore the author selected the universally received approach of principal component analysis to test the construct validity. Six factors whose eigenvalues are greater than 1.5 are extracted and consistent with the hypothesized construct. The communality of every variable is above 0.30 and the cumulative variance of the six factors is $54.645 \%$, which shows each factor contributed a lot to the question investigated (Table 2). In summary, all the data prove the questionnaire has relatively high construct validity.

TABLE 2.

TOTAL VARIANCE EXPLAINED

\begin{tabular}{|l|l|l|l|l|l|l|}
\hline \multirow{2}{*}{ Component } & \multicolumn{5}{|l|}{ Extraction Sums of Squared Loadings } & \multicolumn{4}{l|}{ Rotation Sums of Squared Loadings } \\
\cline { 2 - 7 } & Total & \% of Variance & Cumulative \% & Total & \% of Variance & Cumulative \% \\
\hline 1 & 11.587 & 28.968 & 28.968 & 4.320 & 10.801 & 10.801 \\
\hline 2 & 2.842 & 7.104 & 36.073 & 3.944 & 9.860 & 20.661 \\
\hline 3 & 2.406 & 6.016 & 42.089 & 3.910 & 9.776 & 30.437 \\
\hline 4 & 1.801 & 4.503 & 46.592 & 3.446 & 8.614 & 39.051 \\
\hline 5 & 1.677 & 4.193 & 50.785 & 3.441 & 8.604 & 47.655 \\
\hline 6 & 1.544 & 3.860 & 54.645 & 2.796 & 6.990 & 54.645 \\
\hline
\end{tabular}

\section{Internal Reliability}

The internal reliability of the questionnaire was tested adopting the method of Cronbach Alpha with the help of SPSS. All the six subscales demonstrate great internal reliability value, among which four are between 0.71 and 0.88 with the lowest two are also above 0.58 . The overall internal reliability value is 0.90 (Table 3 ). Therefore, the questionnaire used in this survey shows a relatively high internal reliability.

TABLE 3.

RELIABILITY STATISTICS

\begin{tabular}{|l|l|}
\multicolumn{2}{|c|}{ RELIABILITY STATISTICS } \\
\hline Subscale & Cronbach's Alpha \\
\hline Intrinsic goal orientation & 0.713 \\
\hline self-efficacy for learning and performance & 0.884 \\
\hline meta-cognition & 0.744 \\
\hline time and study environment & 0.598 \\
\hline peer learning & 0.583 \\
\hline Internet self-efficacy & 0.824 \\
\hline overall & 0.904 \\
\hline
\end{tabular}

\section{FINDINGS AND DISCUSSION}

In this section, the results of the survey will be represented in detail, including the illustration of the basic individual 
information of the respondents, the overall situation of students' self-regulatory ability in English learning reflected by data of this survey, the correlations of gender etc. with the final scores of the students' self-regulatory questionnaire, and the situation of the undergraduates' and postgraduates' self-regulation respectively. Detailed and thorough discussion and analysis of these data will follow the presentation of the results.

\section{A. Basic Individual Information of the Respondents}

The survey shows that $22.73 \%$ of all the respondents have taken 2 to 4 courses this term, $21.14 \% 5$ to 6 courses, $29.01 \% 7$ to 8 courses and $26.12 \%$ more. While nearly half of the respondents averagely spend 2 to 4 hours after class on English learning, almost a quarter just learn English in class, and 20.92\% spend 5 to 7 hours. In general, most students spend 0 to 7 hours on English learning after class.

The questionnaires distributed have listed ten different possible reasons why students take this course and each reason is independent from the others. The respondents were asked to give a yes or no answer to each of the ten reasons listed as follow. The data analysis shows that the most popular reason for students' to choose this course is that it is the requirement of their disciplinary setting. Other reasons, for example the course is interesting, useful for other courses, helpful to improve academic skills, and helpful for job seeking, are also significantly popular, as is stated in Table 4.

TABLE 4.

REASONS TO TAKE THIS COURSE

\begin{tabular}{|c|c|}
\hline reasons to take this course & frequency $(\%)$ \\
\hline disciplinary requirement & 91.7 \\
\hline the course is interesting & 73.2 \\
\hline useful for other courses & 75.6 \\
\hline easy to acquire credits & 30.9 \\
\hline helpful to improve academic skills & 70.4 \\
\hline compulsory courses & 73.5 \\
\hline recommended by friends & 21.6 \\
\hline recommended by instructor & 16.1 \\
\hline helpful for job seeking & 68.8 \\
\hline class time is suitable & 71.2 \\
\hline
\end{tabular}

\section{B. Scores of All Respondents}

According to the mean scores of the six subscales, which are relatively low, especially that of the subscale of meta-cognition, the overall ability of DUT students' self-regulation on English learning in a BL context is not very strong. Furthermore, the mean of all respondents' final score is 186.46, which is not high compared with the full mark of the whole questionnaire. This has undoubtedly supported the conclusion drawn through the total score that the self-regulatory ability of DUT students in English BL is not quite strong. Meanwhile, the histogram of the frequency of the total score (Fig. 1) indicates that most respondents' total scores are between 150 and 200, and either extremely high or low scores are rare. This suggests that students' overall self-regulatory ability in English BL is similar.

TABLE 5.

SCORE OF ALL RESPONDENTS

\begin{tabular}{|l|l|l|l|l|}
\hline item & full mark of each subscale & mean & mode & Std. Deviation \\
\hline Intrinsic goal orientation & 28.00 & 20.11 & 22.00 & 4.74 \\
\hline Self-efficacy for learning & 56.00 & 39.65 & 46.00 & 9.57 \\
\hline Meta-cognition & 84.00 & 53.43 & 55.00 & 9.89 \\
\hline Time and study environment & 56.00 & 35.89 & 35.00 & 6.44 \\
\hline Help seeking & 21.00 & 12.00 & 12.00 & 4.01 \\
\hline Internet self-efficacy & 35.00 & 25.39 & 35.00 & 7.31 \\
\hline total & 280.00 & 186.46 & 157.00 & 31.63 \\
\hline
\end{tabular}

Histogram

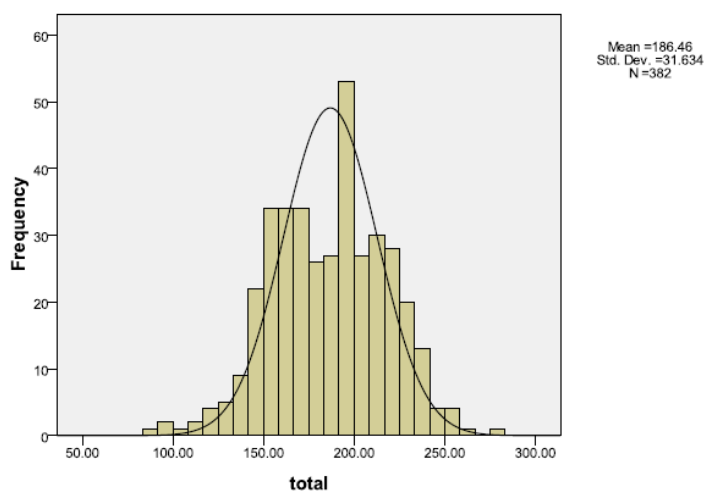

Figure 1. Histogram of the Frequency of All Respondents' Total Score 


\section{Correlations between Gender / Number of Courses / Time / Reasons and Total Score}

In order to investigate whether there are significant correlations between gender / number of courses this term / time spent on this course / reasons taking this course and the total score, the author conducted correlation analysis with the help of SPSS. The output of the analysis shows that none of the correlation coefficients of these items reached 0.40 , which is the critical point of correlation. The conclusion that elements like gender, number of courses this term, average time spent on this course, or reasons taking this course have little correlation with students' self-regulatory ability in English BL is drawn.

TABLE 6.

CORRELATIONS BETWEEN GENDER / NUMBER OF COURSES / TIME / REASONS AND TOTAL SCORE

\begin{tabular}{|l|l|}
\hline items & Pearson Correlation with total score \\
\hline gender & 0.033 \\
\hline how many courses this term & 0.225 \\
\hline average time spent on this course & 0.085 \\
\hline disciplinary requirement & 0.031 \\
\hline the course is interesting & -0.331 \\
\hline useful for other courses & -0.137 \\
\hline easy to acquire credits & -0.051 \\
\hline helpful to improve academic skills & -0.242 \\
\hline compulsory courses & -0.016 \\
\hline recommended by friends & -0.075 \\
\hline recommended by instructor & -0.048 \\
\hline helpful for job seeking & -0.070 \\
\hline class time is suitable & -0.338 \\
\hline
\end{tabular}

\section{Score of Undergraduates}

Comparing the scores of the undergraduate respondents with those of all, it is easy to find that undergraduates' mean score of every subscale is lower than that of overall respondents, which suggests that undergraduates' self-regulatory ability is weaker than the average standard. The mean of the total score of undergraduate respondents is 175.20 , also lower than the average one. Similar to that of all respondents, the histogram of the frequency of undergraduates' total score (Fig. 2) shows the distribution of undergraduates' total scores are centralized, which indicates undergraduates' self-regulatory ability in English BL on the campus of DUT is close to each other.

TABLE 7.

SCORE OF UNDERGRADUATES

\begin{tabular}{|l|l|l|l|l|}
\hline item & full mark of each subscale & mean & mode & Std. Deviation \\
\hline Intrinsic goal orientation & 28.00 & 18.73 & 18.00 & 4.67 \\
\hline Self-efficacy for learning & 56.00 & 37.26 & 46.00 & 9.88 \\
\hline Meta-cognition & 84.00 & 50.48 & 52.00 & 9.28 \\
\hline Time and study environment & 56.00 & 34.20 & 33.00 & 5.66 \\
\hline Help seeking & 21.00 & 11.32 & 14.00 & 3.85 \\
\hline Internet self-efficacy & 35.00 & 23.21 & 35.00 & 7.52 \\
\hline total & 280.00 & 175.20 & 157.00 & 29.74 \\
\hline
\end{tabular}

Histogram

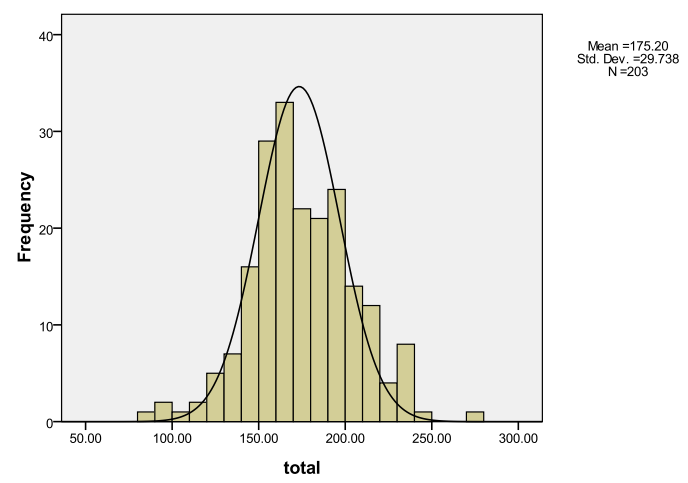

Figure 2. Histogram of the Frequency of Undergraduates' Total Score

\section{E. Score of Postgraduates}

According to the three tables of score (table 5, 7,8), the postgraduate respondents' means of scores of all subscales and the total score as well are all lower than those of undergraduates and those of all, which suggests that the 
postgraduates have stronger self-regulatory ability in English BL than undergraduates. The centralization of postgraduates' total score reflected by the histogram of the frequency (Fig. 3) also verifies that postgraduates' average self-regulatory ability is stronger than that of undergraduates.

TABLE 8.

SCORE OF POSTGRADUATES

\begin{tabular}{|l|l|l|l|l|}
\hline item & full mark of each subscale & mean & mode & Std. Deviation \\
\hline Intrinsic goal orientation & 28.00 & 21.67 & 24.00 & 4.34 \\
\hline Self-efficacy for learning & 56.00 & 42.37 & 46.00 & 8.44 \\
\hline Meta-cognition & 84.00 & 56.77 & 55.00 & 9.52 \\
\hline Time and study environment & 56.00 & 37.80 & 35.00 & 6.75 \\
\hline Help seeking & 21.00 & 12.77 & 12.00 & 4.05 \\
\hline Internet self-efficacy & 35.00 & 27.85 & 35.00 & 6.22 \\
\hline total & 280.00 & 199.23 & 196.00 & 28.80 \\
\hline
\end{tabular}

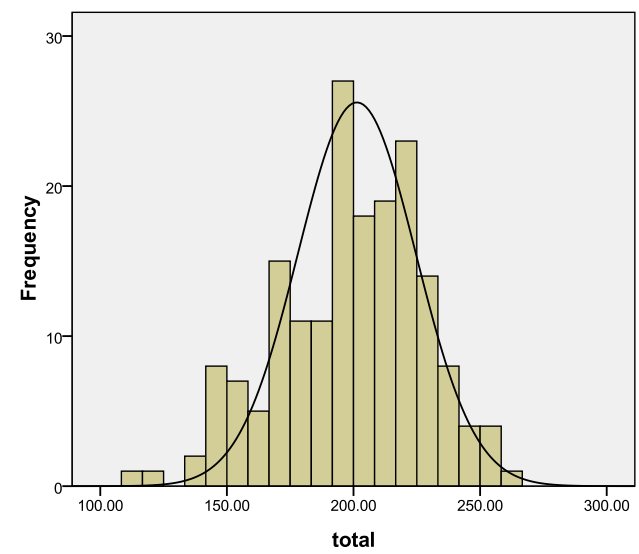

Figure 3. Histogram of the Frequency of Postgraduates' Total Score

\section{F. Contrast of Self-regulatory Ability of Undergraduates and Postgraduates}

According to the score tables of undergraduates and postgraduates, there is difference of the subscale and the total scores between undergraduates and postgraduates. In order to verify whether the difference is obvious or not, an Independent-Samples T Test was conducted with SPSS. The 2-tailed significance of the means of all subscales and the total scores is 0.000 , and 0 is not included in the $95 \%$ confidence interval of the mean difference. Therefore, a conclusion that the difference of undergraduates' and postgraduates' scores is significant can be reached. In other words, the self-regulatory ability of the undergraduates and postgraduates is distinctly different.

TABLE 9.

INDEPENDENT-SAMPLES T TEST

\begin{tabular}{|c|c|c|c|c|c|c|c|c|c|}
\hline \multirow{3}{*}{ items } & \multicolumn{2}{|c|}{$\begin{array}{l}\text { Levene's } \\
\text { Equality for } \\
\text { Variances }\end{array}$} & \multicolumn{7}{|c|}{ T-test for Equality of Means } \\
\hline & \multirow[b]{2}{*}{$\mathrm{F}$} & \multirow[b]{2}{*}{ Sig. } & \multirow[b]{2}{*}{$\mathrm{t}$} & \multirow[b]{2}{*}{$\mathrm{df}$} & \multirow[b]{2}{*}{$\begin{array}{l}\text { Sig. } \\
\text { (2-tailed) }\end{array}$} & \multirow[b]{2}{*}{$\begin{array}{l}\text { Mean } \\
\text { Difference }\end{array}$} & \multirow[b]{2}{*}{$\begin{array}{l}\text { Std. Error } \\
\text { Difference }\end{array}$} & \multicolumn{2}{|c|}{$\begin{array}{l}95 \% \text { Confidence } \\
\text { Interval of the } \\
\text { Difference }\end{array}$} \\
\hline & & & & & & & & Lower & Upper \\
\hline $\begin{array}{l}\text { Intrinsic } \\
\text { orientation }\end{array}$ & 1.595 & 0.207 & -6.351 & 380 & 0.000 & -2.941 & 0.463 & -3.852 & -2.030 \\
\hline $\begin{array}{l}\text { Self-efficacy for } \\
\text { learning }\end{array}$ & 9.722 & 0.002 & -5.448 & 379.635 & 0.000 & -5.108 & 0.937 & -6.951 & -3.264 \\
\hline Meta-cognition & 0.132 & 0.717 & -6.526 & 380 & 0.000 & -6.283 & 0.963 & -8.175 & -4.390 \\
\hline $\begin{array}{l}\text { Time and study } \\
\text { environment }\end{array}$ & 11.452 & 0.001 & -5.617 & 348.934 & 0.000 & -3.607 & 0.642 & -4.871 & -2.344 \\
\hline Help seeking & 0.629 & 0.428 & -3.584 & 380 & 0.000 & -1.451 & 0.405 & -2.247 & -0.654 \\
\hline $\begin{array}{l}\text { Internet } \\
\text { self-efficacy }\end{array}$ & 11.591 & 0.001 & -6.604 & 378.487 & 0.000 & -4.643 & 0.703 & -6.025 & -3.261 \\
\hline total & 0.121 & 0.728 & -7.999 & 380 & 0.000 & -24.033 & 3.005 & -29.940 & -18.125 \\
\hline
\end{tabular}

G. Possible Reasons for the Difference between Undergraduates and Postgraduates 
According to the analysis of all the research data, there exists an obvious difference of self-regulatory ability in English BL between undergraduates and postgraduates on the campus of DUT. A number of reasons, among which three may be particularly significant, can lead to this result.

First, comparing the scores of the subscales of intrinsic goal orientation and self-efficacy for performance, one can easily find that postgraduates outscore undergraduates in this sector, i.e. motivation. Thus postgraduates may be more motivated than their counterparts in English learning, which can help adopt better learning strategies and achieve better results. The positive motivation of postgraduates may result from their clear awareness of the significance of English learning in academic study and future job seeking as well.

Second, as to the subscales of meta-cognition and time and place environment management, which are important self-regulated learning strategies, generally the postgraduates have gained higher scores. This may imply that through two or three more years' learning and practice, postgraduates may have accumulated more self-regulated learning strategies skills and thus are better at self-regulation.

Third, postgraduates achieved better than undergraduates in the subscale of Internet efficacy, which suggests that most postgraduates have a better mastery of computers and the Internet. Two or more years' adoption of modern technologies of computer and Internet in learning may help students strengthen their self-efficacy and mastery of computer use.

In summary, more years' learning and practice will enhance learners' self-regulatory ability in BL, which is one major reason to justify the fact that postgraduates have stronger self-regulatory ability in English BL.

\section{H. Suggestions to Improve Students'Self-regulatory Ability}

By comparing the research results of the undergraduates and postgraduates, it's concluded that more years' learning and practice will enhance learners' self-regulatory ability in a BL context, as mentioned in the former part. Hence some empirical suggestions are provided for both instructors and students to improve learners' self-regulatory ability in BL through years of teaching and learning on campus.

In order to figure out what effective measures can be taken in course learning, several points of guiding principles should be highlighted. Foremost, the instructors should help students fully understand their leading role in learning. This is extremely significant in that traditional teaching have overly emphasized the role of the instructors in learning, which has led to students' undue independence on their instructors. Accordingly, it is crucial for students to establish and enhance the awareness of learners-centered teaching and learning modality. Measures to improve students' self-regulatory ability can only be effective and efficient on the basis of this keen awareness. Second, after acquiring the awareness of students-centered teaching and learning, students have to gain the knowledge of self-regulation: its meaning, connotation, implication and significance, for one can only truly master a skill or craft after knowing what it is. Understanding how self-regulation is composed, students can purposefully take actions to improve themselves. Third, it will be better if instructors set examples or models to explain specific self-regulatory strategies since examples and models can provide students a clearer and more concrete comprehension rather than a mere abstract concept. Fourth, the process of the improvement of one's self-regulatory ability always extends a relatively long period, say two or three years or longer. In addition, it is also an unbroken and progressive process which can not be completed without efforts and setbacks. Thus it requires both instructors and learners to be patient and persistent in the long term. Fifth, constant interactions between instructors and students can provide instructors more opportunities to be familiar with their students and students' problems. So instructors should try their best to create opportunities to communicate with students, making full use of various tools including modern technology of communication. Ultimately, timely feedback is an indispensable element which can help students find out their own shortcomings and weaknesses and thus better direct their subsequent efforts accordingly.

Keeping the general principles in mind and considering the specific situation on the campus of DUT, the author offers following suggestions to enhance students' self-regulated ability. First, instructors of English courses may more explain to their students the importance and necessity of English learning in academic study and future career as well. As a result, students can be more motivated in English learning. Second, more interactions between instructors and students in class can make the English courses more interesting and attracting. Activities, like debates on related themes, short plays of given scenarios, prompt speeches on hot issues, to name a few, can greatly liven up the atmosphere of class. Meanwhile, these activities can also cultivate cooperation and teamwork of students and thus promote peer learning among classmates. Third, instructors can hold some English learning experience exchange meetings wholly in English. On one hand, students can have an opportunity to practice their spoken English. On the other hand, students can acquire some helpful English learning and self-regulatory strategies. In addition, instructors can directly teach their students the components and application of common learning strategies. Fourth, instructors and students may constantly share information about useful and helpful English learning websites and software to strengthen students' self-efficacy in computer and Internet.

In summary, both instructors and students should establish a keen awareness of students-centered teaching and learning modality in the first position in a BL context. In addition, instructors can increase students' interest in English learning by enrich the content and form of English courses. Furthermore, self-regulatory learning strategies should be continually emphasized during the whole process of English learning. Ultimately students' self-regulatory ability can gradually be enhanced. 


\section{CONCLUSION AND IMPLICATION}

\section{A. A Theoretical Framework of Self-regulation in Blended Learning}

Despite the fact that Blended Learning has become a research focus in higher education, studies on students' self-regulation in a BL context are rare. Based on former studies and theories concerning BL and self-regulation, the author rearranged and generalized a theoretical framework of self-regulation in English learning in a BL context for her survey.

BL is a teaching and learning modality that combines traditional face-to-face teaching method and any form of instructional technology (e.g. videotape, CD-ROM, web-based materials) in order to maximize both the guidance of professors and the initiation of students. One of the most significant determinants of the outcome of BL is self-regulation regarding to the features of BL. Five self-regulatory attributes, i.e. motivation, meta-cognition, time and environment management, help seeking and Internet self-efficacy, are the main determinants of the success of learning in a BL context. With this theoretical framework of self-regulation in BL, the author constructed a questionnaire adapted from Pintrich's Motivated Strategies for Learning Questionnaire (MSLQ) to assess the self-regulatory ability of students in English learning in DUT.

\section{B. Status Quo in DUT's BL Context}

The analysis of the data collected in this survey using the statistical software Statistical Package for Social Science (SPSS) indicates that students in DUT do not have relatively strong self-regulatory ability in English learning in the BL context. Meanwhile, the outcome also implies that postgraduates' self-regulatory ability is stronger than that of undergraduates. The outcome also supports the argument that students' self-regulatory ability can be enhanced through teaching, learning and practice. Therefore, the author suggests that measures should be taken to increase students' motivation for English learning, self-efficacy for the Internet, and what's more, learning strategies like meta-cognition and management of time and place by enriching the content and form of English courses, directly teaching learning strategies, sharing useful English learning websites, enhancing awareness of peer learning and teamwork, increasing interactions between students and instructors, etc. With years of learning and practice, students can undoubtedly strengthen their self-regulatory ability, which will not only improve their academic skills but also benefit their future career.

\section{Recommendations for Further Study}

This study addresses the overall situation of students' self-regulatory ability in English learning in a BL context on the campus of DUT, instead of students' mastery of specific learning strategies or efficiency of course design. Subsequently the outcome is merely a rough panorama of the current situation. Therefore, studies of what learning strategies are better mastered by students, what should be strengthened, and how to design the English courses may be conducted. In addition, the instrument of this study is mere one questionnaire, which has a lot limitation on reflecting the reality and details. Further studies can be conducted using more complex measures such as structured interviews, teacher judgments, or a measure process combining these three methods in order to get detailed, refined and accurate results.

\section{REFERENCES}

[1] Artino A. R. Jr. (2005). A review of the motivated strategies for learning questionnaire. http://www.sp.uconn.edu/ aja05001/comps/documents/MSLQ_Artino.pdf (accessed 20/5/2010).

[2] Ayala J. S. (2009). Blended learning as a New approach to social work education. Journal of Social Work Education, 45.2, 277-288.

[3] Cui, H. P. (2005). Blended Learning: the Only Road to Educational Informanization. Primary and Middle School Audiovisual Education, 11, 4-6.

[4] Dong, Q. \& Zhou, Y. (1994). Self-Regulation in Students' Learning. Journal of Beijing Normal University (Social Science Edition), 1, 8-14.

[5] Driscoll. (2002). Blending learning: Let's get beyond the hype, E-learning. http://elearningmag.com.timagazine (accessed 20/5/2010).

[6] Flavell, J. H. (1987). Speculations about the nature and development of metacognition. In F. E. Weinert \& R. H. Kluwe (Eds.), Metacognition, motivation and understanding. Hillside, New Jersey: Lawrence Erlbaum Associates, 21-29.

[7] He, K. K. (2004). Development of Education Technology Theories Based on Blending Learning. E-education Research, 3, 1-6.

[8] Li, G. Y. (2008). Philosophy of Blended Learning and its inspirations on Teaching. Software Guide, 3, 7-9.

[9] Li, H. L. (2004). Research Advancement on Computer Self-Efficacy. Advances in Psychological Science, 12, 561-566.

[10] Liu, W. Y. \& Zha, J. A. (2009). Motivation Orientation in a Web-Based Environment. Foreign Language Research, 3, 121-123.

[11] Liu, X. Y. (2005). An Empirical Research on Internet Self-efficacy for College Students in Shanghai. Ph.D. dissertation, Shanghai Normal University.

[12] Livingston J. A. (1997). Metacognition: An overview. http://gse.buffalo.edu/fas/shuell/cep564/metacog.htm (accessed 20/5/2010)

[13] Lynch R. \& Dembo M. (2004). The relationship between self-regulation and online learning in a blended learning context. International Review of Research in Open and Distance Learning, 5.2.

[14] Means, B., Toyama, Y., Murphy, R., Bakia, M., Jones, K. (2009). Evaluation of evidence-based practices in online learning: A 
meta-analysis and review of online learning. Center for Technology in Learning, U.S. Department of Education. http://www.ed.gov/rschstat/eval/tech/evidence-based-practices/finalreport.pdf (accessed 20/5/2010).

[15] Montalvo F. T. \& Torres M. C. G. (2008). Self-regulated learning: Current and future directions. Electronic Journal of Research in Educational Psychology, 2.1, 1-34.

[16] Pincas A. \& Saunders G. (2003). Getting started with ICT blended learning. Academic Exchange, 12.7, $225-228$.

[17] Pintrich P. R. \& De Groot E. V. (1990). Motivational and Self-Regulated Learning Components of Classroom Academic Performance. Journal of Educational Psychology, 82.1, 33-40.

[18] Pintrich, P. R., et al. (1991). A manual for the use of the motivated strategies for learning questionnaire. Michigan: The University of Michigan.

[19] Rovai A. P. \& Jordan H. M. Blended learning and sense of community: A comparative analysis with traditional and fully online graduate courses. The International Review of Research in Open and Distance Learning, 5.2.

[20] Zimmerman, B. J. (1989). A social cognitive view of self-regulated academic learning. Journal of Educational Psychology, 81.3, $329-339$.

[21] Zimmerman, B. J. (2002). Becoming a self-regulated learner: an overview. Theory into Practice, 41.2, 64-70.

Haibo Shen is now studying in Dalian University of Technology as a master candidate. Her research interests are ESL learning strategy and computer assisted language learning. The paper is based on a project sponsored by Dalian University of Technology.

Wenyu Liu received his Ph.D. from Dalian University of Technology and now is a Professor in the School of Foreign Languages at Dalian University of Technology. He has been teaching since 1993. From 2009 to 2010, he worked at the University of Minnesota Twin cities, the U.S.A. as a Fulbright research scholar. His research interests are teaching English as a second or foreign language, computer assisted language learning and neurolinguistics. 